\title{
Effects of per-household processes on the levels of chlorpyrifos residues in lettuce (Lactuca sativa)
}

\author{
Osei Akoto ${ }^{1 *}$, Fredrick Addai-Mensah² and Eric K. K. Abavare ${ }^{3}$
}

\begin{abstract}
Background: The study was organized to evaluate residue levels of chlorpyrifos on Lactuca sativa that are likely to have accumulated on crop during cultivation and also examine the effect some pre-household treatment procedure on residue levels on the crop grown in a tropical and humid environment. Chlorpyrifos residue was extracted using acetonitrile. Subsequent detection and a quantification were done using GC with PFPD. Concentrations of Chlorpyrifos applied at different stages of growth of lettuce were examined at different time intervals of 1 h, $24 \mathrm{~h}$ and 7 days after pesticide application.

Results: The results showed that residue levels detected at $1 \mathrm{~h}$ and $24 \mathrm{~h}$ after application were all above the MRL of $0.05 \mathrm{mgkg}^{-1}$ and can pose health risk to consumers while that recorded 7 days after application were far below the MRL. Accumulation of chlorpyrifos on crop during cultivation was not observed since no significant differences were observed 7 days after application at all the different stages. There is therefore the need for farmers to allowed 7 days' re-entry intervals before harvesting. The results also showed that, all the pre-household treatment procedures caused significant reduction in residues levels of chlorpyrifos on the crop.

Conclusions: Mild detergent treatment was however more effective compared with the other treatments. Hence to reduce the risk associated with intake of chlorpyrifos through lettuce, mild detergent washing procedures should be followed before consumption.
\end{abstract}

Keywords: Chlorpyrifos, Consumers, Health risk, Removal, Treatments

\section{Background}

Consumption of diets high in fresh vegetables by Ghanaians is growing. This is because vegetables are universally endorsed as healthy. Thus, they supply high amount of vitamins, antioxidants and dietary fiber which is linked to lower incidence of cardiovascular disease and obesity (Slavin and Lloyd, 2012). Lettuce (Lactuca sativa) is an important vegetables cultivated and consumed by both urban and rural dwellers in Ghana. Because of this increase in consumption, lettuce is now cultivated all year round in large quantities. However, pests and diseases militate against the successful cultivation of the crop. As a result, pesticides are use in the production of the crop (Akoto et al., 2013; Gerken et al., 2013).

\footnotetext{
* Correspondence: wofakmann@yahoo.com

${ }^{1}$ Department of Chemistry, Kwame Nkrumah University of Science and

Technology, Kumasi, Ghana

Full list of author information is available at the end of the article
}

Due to the inability of farmers to apply appropriately the prescribed dosage of the pesticides at every stage of the crop production, and unaware of their possible health effect on humans and the environment, large quantities of pesticides are used (Obeng-Ofori et al., 2002). Again the high demand for vegetables, causes farmers to harvest their produce without taking into account the pesticide withholding period (Amoah et al., 2006; Bhanti and Taneja, 2007). The increased and inappropriate use of pesticides in vegetable production in Ghana has led to an increase of residues on the crop above the MRL (Akoto et al. 2015; Obeng-Ofori et al., 2002). In Ghana, pesticide residues including that of chlorpyrifos have been found at concentrations above the acceptable limits in lettuce (Amoah et al., 2006), shallots (Kotey et al., 2008) and tomatoes (Essumang et al., 2008) that have not been subjected to any household treatment procedures.

Chlorpyrifos (O,O-diethyl O-3,5,6-trichloro-2-pyridyl phosphorothioate) a contact organophosphate insecticide 
is intensively used by farmers as a protective measure against pests and diseases on lettuce (Clark et al., 1997). Chlorpyrifos is toxic to humans and can be absorbed through all routes of exposure. Signs of severe toxicity include increased heart rate, unconsciousness, convulsions, respiratory depression, and paralysis (Reigart and Roberts, 1999; Thompson and Richardson, 2004).

Studies have shown that certain types of post-harvest treatments or pre-household preparations such as washing, drying and boiling at different temperatures may help to reduce pesticide residues (Kim et al., 2015; Dhiman et al., 2006; Krol et al., 2000). The effects of these household treatments on residue levels are extremely important in evaluating the risk associated with ingestion of pesticides residues through vegetable consumption. But information on household treatment procedure on chlorpyrifos residue in vegetables such as lettuce is very scarce. The objectives of the study were to measure chlorpyrifos residue levels in lettuce and examine the effect of pre-household treatment procedures on the residues.

\section{Methods Sampling}

Pesticides were applied at three different stages during growth. At stage 1, pesticides were applied week 1 after the seedlings transplant, at stage 2 pesticides application was done week 3 after transplant of seedlings and at stage 3 application was done week 5 after the seedlings have been transplanted. Sampling of lettuce for residue analysis was done at three different stages during growth (stage 1, stage 2 and stage 3). At each stage, fresh lecture samples were collected at different time intervals thus $1 \mathrm{~h}, 12 \mathrm{~h}$ and 7 days after pesticide application.

The samples were labeled, wrapped in aluminum foil and transported to the laboratory immediately after collection in ice box. Samples were then cut into small pieces, mixed thoroughly and $100 \mathrm{~g}$ sub-samples weighed for each prehousehold treatment procedure. Samples were subjected to three (3) pre-household treatment procedures, thus: washing under running tap water for 2 min (Treatment 2), dipping in $500 \mathrm{~mL} 2 \%$ salt solution at room temperature for $2 \mathrm{~min}$ (Treatment 3) and dipping in $500 \mathrm{~mL} 1 \%$ detergent solution $(\mathrm{v} / \mathrm{v})$ at room temperature for $2 \mathrm{~min}$ (Treatment 4). The treated samples were left for $1 \mathrm{~h}$ in colander to drain at room temperature (Kim et al., 2015). The forth sample was analysed without any pre-household treatment and were considered as the control samples (Treatment 1).

\section{Extraction and GC analysis of pesticide residue}

Two (2) grams of homogenized sample was mixed with $5 \mathrm{~mL}$ of acetonitrile in a separating funnel. The mixture was shaken with for one hour on a rotatory shaker. After shaking, the separating funnel was allowed to stand to settle and the acetonitrile layer was decanted into a round bottom flask. This procedure was repeated twice and the extracts combined. The combined acetonitrile phase was centrifuge for $2 \mathrm{~min}$ at $3000 \mathrm{rpm}$ and the supernatant transferred in a graduated vial. The extracts were concentrated to about $2 \mathrm{~mL}$ using a rotary evaporator operating at temperature of $30 \mathrm{C}$ at a reduced pressure. The extract was made up to $2 \mathrm{~mL}$ with acetonitrile before GC injection.

Levels of chlorpyrifos residue were analyzed using Agilent Tech. 6890 N GC equip with pulse flame photometric detector (PFPD), coupled with Chemito 5000 data processor with a HP- 5 capillary column $(30 \mathrm{~m} \times 0.32 \mathrm{~mm}$ id.) of $0.25 \mu \mathrm{m}$ film thickness. The GC analysis was performed under the following condition. Oven temperature was $210{ }^{\circ} \mathrm{C}$, Injector temperature was $230{ }^{\circ} \mathrm{C}$, column temperature was $160{ }^{\circ} \mathrm{C}$ and detector temperature was $300{ }^{\circ} \mathrm{C}$. Carrier gas was nitrogen at a flow rate of $2 \mathrm{~mL} \min ^{-1}$.

\section{Quality control measures}

Recovery analyses were carried out on samples fortified at $0.001 \mathrm{mg} \mathrm{kg}^{-1}$ by adding standard chlorpyrifos solution. The recovery values were calculated from calibration curves constructed from the concentration and peak area of the chromatograms obtained with standards of chlorpyrifos. The recovery of the pesticide was in the range between 80 and $110 \%$. Blank analyses were also performed in order to check interference from the sample. For quality control of the gas chromatographic conditions, a checkout procedure was performed before sample analysis.

\section{Results and discussion}

Physical removal of pesticide residue from a crop is a way of reducing the concentration of the pesticide below acceptable levels. Pesticide residues below acceptable levels implies that the crops are safer for consumption by humans and that there is no expected health implication associated with the consumption of the product. Prehousehold treatment procedures are used commercially and in the home to reduce pesticide residues concentrations to levels below the MRL value. Pre-household treatment procedures used in this study were washing under running tap water (Treatment 2), dipping in salt water for 2 min (Treatment 3 ) and dipping in $1 \%$ detergent solution for 2 min (Treatment 4).

Mean concentrations of chlorpyrifos residues detected in the lettuce samples after subjecting them to the various household treatment procedures and that of the control at all the three (3) different stages of growth are presented in Table 1. Residue levels detected in the control samples (Treatment 1 ), $1 \mathrm{~h}$ after treatment with chlorpyrifos were $0.059 \pm 0.008,0.055 \pm 0.0014$ and $0.055 \pm$ $0.009 \mathrm{mgkg}^{-1}$ for stage 1 , stage 2 and stage 3 respectively. The detected mean residues in the lettuce samples at all 
Table 1 Means and standard deviations of chlorpyrifos residue levels $\left(\mathrm{mg} \mathrm{kg}^{-1}\right)$ in the treated and control lettuce samples at different stages of growth, $n=6$

\begin{tabular}{|c|c|c|c|c|c|c|c|c|c|}
\hline \multirow[b]{2}{*}{ Treatments } & \multicolumn{3}{|l|}{ Stage 1} & \multicolumn{3}{|l|}{ Stage 2} & \multicolumn{3}{|l|}{ Stage 3} \\
\hline & Sample 1A & Sample 2A & Sample 3A & Sample 1B & Sample 2B & Sample 3B & Sample 1C & Sample $2 \mathrm{C}$ & Sample 3C \\
\hline Control/Treatment 1 & $0.059 \pm 0.008$ & $0.052 \pm 0.001$ & $0.006 \pm 0.002$ & $0.055 \pm 0.0014$ & $0.053 \pm 0.012$ & $0.007 \pm 0.002$ & $0.055 \pm 0.009$ & $0.034 \pm 0.003$ & $0.002 \pm 0.001$ \\
\hline Treatment 2 & $0.049 \pm 0.009$ & $0.048 \pm 0.004$ & $0.006 \pm 0.001$ & $0.052 \pm 0.004$ & $0.046 \pm 0.007$ & $0.005 \pm 0.0028$ & $0.053 \pm 0.0023$ & $0.03 \pm 0.006$ & $0.002 \pm 0.0014$ \\
\hline Treatment 3 & $0.039 \pm 0.006$ & $0.023 \pm 0.004$ & $0.004 \pm 0.001$ & $0.041 \pm 0.008$ & $0.035 \pm 0.004$ & $0.004 \pm 0.0014$ & $0.043 \pm 0.0014$ & $0.025 \pm 0.004$ & $0.002 \pm 0.0004$ \\
\hline Treatment 4 & $0.018 \pm 0.006$ & $0.01 \pm 0.004$ & $0.003 \pm 0.001$ & $0.028 \pm 0.009$ & $0.027 \pm 0.004$ & $0.004 \pm 0.002$ & $0.027 \pm 0.003$ & $0.019 \pm 0.008$ & $0.001 \pm 0.001$ \\
\hline
\end{tabular}

the 3 stages of growth were above the Maximum Residue Level (MRL) of $0.05 \mathrm{mgkg}^{-1}$ (FAO/WHO, 2004). The mean concentrations of chlorpyrifos in the control samples, $24 \mathrm{~h}$ after application at all the stages of growth were also very high and were above the MRL as presented in Table 1. This is in agreement with the observation made by Amoah et al., 2006, where residues of chlorpyrifos in lettuce were observed to be above the MRL value. The levels of chlorpyrifos at all the different stages of growth were drastically reduced to mean concentrations of $0.006 \pm 0.002,0.007 \pm 0.002$ and $0.002 \pm 0.00 \mathrm{mgkg}^{-1}$ for stage 1 , stage 2 and stage 3 respectively. These reductions in chlorpyrifos levels were observed 7 days after application. These mean levels were far below the MRL of chlorpyrifos in lettuce.

Levels of chlorpyrifos in the lettuce samples at all the different stages of growth after tap water treatment $\left(\mathrm{T}_{1}\right)$ are presented in Table 1. The mean concentrations of chlorpyrifos in samples from this treatment, $1 \mathrm{~h}$ after application were $0.049 \pm 0.009,0.052 \pm 0.004$ and $0.053 \pm$ $0.0028 \mathrm{mgkg}^{-1}$ for stage 1 , stage 2 , and stage 3 respectively. All the values were lower than the MRL value. The differences in the concentrations of chlorpyrifos in the control (Treatment 1) and Treatment 2 samples, $1 \mathrm{~h}$ after application were not significant $(P>0.05)$ at all the different stages of growth. Chlorpyrifos residues detected in Treatment 2 samples, $24 \mathrm{~h}$ after application were $0.048 \pm$ $0.004 \mathrm{mgkg}^{-1}$ at growth stage $1,0.04 \pm 0.007 \mathrm{mgkg}^{-1}$ at growth stage 2 and $0.03 \pm 0.006 \mathrm{mgkg}^{-1}$ at growth stage 3 (Table 1). The differences between the control samples and the Treatment 2 samples $24 \mathrm{~h}$ after pesticides application were not significant at all the 3 stages of growth. Again no statistical differences were observed among the Treatment 2 samples $24 \mathrm{~h}$ after application at the different growth stages. Residues of chlorpyrifos, 7 days after application followed by Treatment 2 at the different stages of growth were $0.006 \pm 0.001,0.005 \pm$ 0.0028 and $0.002 \pm 0.0014$ for stage 1 , stage 2 and stage 3 respectively. Differences between Treatment 2 and control samples, 7 days after application were significant $(p<0.05)$ but no significant variations were observed between the treated (Treatment 2) samples at the different growth stages. It was noted that washing with tap water reduced chlorpyrifos levels to $4-16 \%$ compared to those in the untreated (control samples). This finding doesn't agree with that by Ling et al. (2011), who reported a decrease rate of $0.23 \%$ of chlorpyrifos in lettuce. This difference may be due to the types of adjuvants added during formulation. Some formulation with binders held pesticides firmly onto the applied surface. Other studies have reported decreased rate of $3.65,10.6,36.3$ and $46.6 \%$ of chlorpyrifos residues in galic sprouts, cucumber, eggplant and tomatoes respectively after washing with tap water (Kim et al., 2015).

The effectiveness of washing as a household treatment procedure to remove pesticide residues on the surface of a vegetable varies but depends on the physicochemical properties of the compound, age of residue, surface area of leave and nature and thickness of the cuticle. (LopezFern et al., 2013; Ling et al., 2011; Kumari, 2008). Chlorpyrifos is a non-systemic insecticide and therefore would be located on the surface of the leaves after its application. The loosely bound surface residues of chlorpyrifos were therefore removed by washing under tap water. However, $22.2 \%$ of the samples that were collected $1 \mathrm{~h}$ after chlorpyrifos application and subjected to Treatment 2 had residue levels above the MRL of $0.05 \mathrm{mgkg}^{-1}$ (FAO/WHO, 2004) for chlorpyrifos on lettuce. Treatment 2 was ineffective in removing chlorpyrifos from the surface of the lettuce. The variations in the levels of chlorpyrifos on the lettuce samples after Treatment 2 were not significant at $5 \%$ significance level from that of the control treatment (Treatment 1). This may be due to the fact that chlorpyrifos is not soluble in water and again the surface of the lettuce leaves are lined with thing layer of cuticle and therefore making the binding of the compound to the surface stronger.

Mean and the standard deviation of chlorpyrifos residue levels detected in lettuce after salt water washing (Treatment 3) for all the different stages of growth are presented in Table 1 . The mean residue levels observed for samples treated with salt water wash during the first stage of growth were $0.039 \pm 0.006,0.023 \pm 0.004$ and $0.004 \pm 0.001 \mathrm{mgkg}^{-1}$ for samples that were taken at $1 \mathrm{~h}$, $24 \mathrm{~h}$, and 7 days after pesticide application respectively. During the second stage of growth, the residue levels at the different sampling time after Treatment 3 were $0.049 \pm 0.008,0.03 \pm 0.004$ and $0.004 \pm 0.0014 \mathrm{mgkg}^{-1}$ for 
$1 \mathrm{~h} 24 \mathrm{~h}$ and 7 days after pesticide application respectively. Chlorpyrifos residues detected during the third stage of growth of lettuce were $0.043 \pm 0.001,0.025 \pm$ 0.004 and $0.002 \pm 0.0004 \mathrm{mgkg}^{-1}$ for samples that were collected at $1 \mathrm{~h}, 24$, $\mathrm{h}$ and 7 days after pesticide application respectively. Levels of chlorpyrifos detected in all the samples after washing with salt solution for $2 \mathrm{~min}$ were below the MRL. Relatively lower levels of chlorpyrifos were detected in the samples that were taken at $1 \mathrm{~h}$ after application and treated with salt solution (Treatment 3) when compared with the control samples (Treatment 1 ) at all the different growth stages. The percentage reduction of chlorpyrofos was found to be in a range of 35-43\% in the samples that were collected $1 \mathrm{~h}$ after application and treated with salt solution (Treatment 3 ) at the different growth stages.

Chlorpyrifos residue detected in lettuce after detergent washing (Treatment 4) are presented in Table 1. The detected residue levels observed during the first stage of growth of lettuce after treatment $T_{3}$ was $0.015 \pm 0.004$, $0.01 \pm 0.004$ and $0.003 \pm 0.0008 \mathrm{mgkg}^{-1}$ for the samples that were collected at $1 \mathrm{~h}, 24 \mathrm{~h}$ and 7 days after pesticide application respectively. During the second stage of growth of lettuce, the detected residue levels observed were $0.048 \pm 0.0098,0.027 \pm 0.004$ and $0.004 \pm$ $0.0019 \mathrm{mgkg}^{-1}$ for samples that were taken at $1 \mathrm{~h} 24 \mathrm{~h}$ and 7 days after pesticide application respectively. The detected residue levels on lettuce that was observed during the third stage of the growth of lettuce were $0.048 \pm 0.0056,0.019 \pm 0.0098$ and $0.001 \pm 0.00028 \mathrm{mgkg}^{-1}$ for samples that were collected at $1 \mathrm{~h}, 24 \mathrm{~h}$ and 7 days after pesticide application respectively.

Residue detected on foliage were high in the control samples that were collected $1 \mathrm{~h}$ and $24 \mathrm{~h}$ after pesticide application at all the different stages of growth, but the detected levels were very low and even below detection limit in some of the samples that were analysed 7 days after application.

This insecticide had direct contact with the leaves and remained on the leaves after application. This was evident from the results since the highest recorded residue level at all the different stages of growth were recorded $1 \mathrm{~h}$ after application (Table 1). A gradual and continuous deterioration of the chlorpyrifos residues on the lettuce leaves were observed as a function of time (days) after pesticide application. The decrease in the residue concentration of chlorpyrifos on foliage over time may be due to factors such as volatilization and/or photodegradation. Chlorpyrifos adsorbed on leaf surfaces are usually lost through volatilization especially in hot climates (Roberts and Hutson, 1999). Volatilization may have been a factor to the reduced levels of the chlorpyrifos on the lettuce since this study was carried on a hot climatic region where temperatures are high. Temperature influenced pesticide dissipation on plant through volatilization and photodegradation. Obviously, a higher temperature tends to favour volatilization and photodegradation of pesticides from plants, because the vapour pressure of the pesticide compound is temperature-dependent and additionally the extent of adsorption to the leaf surface decreases with increasing temperature.

According to Smith (1968), chlorpyrifos when exposed to sunlight, undergoes hydrolysis in the presence of water to liberate 3, 5, 6-trichloro-2-pyridinol (TCP), which undergo further decomposition to diols and triols and ultimately cleavage of the ring to fragmentary products. Therefore, photodegradation may be a factor to cause reduction in residue concentration of chlorpyrifos since the crops were watered regularly after pesticides application.

Dissipation of chlorpyrifos took place causing a reduction in the detected residue levels that was observed $1 \mathrm{~h}$ after pesticide application. Thus after $1 \mathrm{~h}$ of application of chlorpyrifos, the mean detected residue levels were $0.059 \pm 0.008,0.055 \pm 0.001$ and $0.055 \pm 0.009 \mathrm{mgkg}^{-1}$ for the first, second and third growth stages respectively in the control samples. After $24 \mathrm{~h}$, the mean residue levels reduced to $0.052 \pm 0.001,0.053 \pm 0.012$ and $0.034 \pm$ $0.003 \mathrm{mgkg}^{-1}$ for the first, second and third growth stages respectively. There was a mean percentage reduction of $17.9 \%$ of initial residue levels detected $1 \mathrm{~h}$ after pesticide application. After 7 days of pesticide application, the detected residue levels further reduced to $0.006 \pm 0.002,0.007 \pm 0.002$ and $0.002 \pm 0.00 \mathrm{mgkg}^{-1}$ for the first, second and third growth stages respectively. There was a mean percentage reduction of $91.1 \%$ of initial residue levels detected $1 \mathrm{~h}$ after pesticide application. This shows that if farmers will allow 7 days' intervals after application of chlorpyrifos on lettuce before harvest the levels of residues will be reduced far below the MRL if the pesticide is properly applied at a hot climate region.

Stage of growth at which pesticide is applied and frequency of application during growth are important factor that affect residue levels and dissipation rate on a crop. In this work relatively higher concentration of chlorpyrofos residues were observer on stage 1 samples than stage 2 and stage 3 samples that were collected at $1 \mathrm{~h}$ after application. This may be due to high density of applied pesticide on the foliage which have small surface area. But at the second and third stages the leaves sizes were larger and have large surface area therefore the applied pesticides spread to cover the whole surface thereby reducing the concentration of the pesticide. The rete of pesticide degradation was fast with the second and the third stages of the growth than the first stage. This was because the foliage sizes at the second and the third stages were larger than the first stage this provided large surface areas for volatalisation. Mean percentage reduction of $38.1 \%$ and 
$96.3 \%$ were observed $24 \mathrm{~h}$ and 7 days after application respectively on the control samples.

Results from this study show that, detergent is more effective in reducing chlorpyrifos levels on lettuce than washing with tap water and washing with salt solution. Dipping lettuce in $1 \%$ detergent (Treatment 4 ) reduced the residues by a mean percentage of $54.4 \%$, whiles salt water washing caused a mean percentage reduction of $30.8 \%$. It was 3.7 times more effective than tap water wash and 1.6 times more effective than salt water washing. The levels of chlorpyrifos in all the samples were far below MRL set for chlorpyrifos on lettuce (FAO/WHO, 2004) after Treatment 4.

According to Hui et al., 2010, the rate of hydrolysis of chlorpyrifos increases with $\mathrm{pH}$ and also the stability of chlorpyrifos decreases as the $\mathrm{pH}$ increases. Smith, 1968 also stated that, hydrolysis of chlorpyrifos occurs readily at $\mathrm{pH}>7$. Detergent which was used in Treatment 4 caused an increase in the $\mathrm{pH}$ of aqueous solution. This resulted in destabilizing chlorpyrifos residue levels on the lettuce resulting in higher removal of chlorpyrifos. For instance, the residue level detected $1 \mathrm{~h}$ after pesticide application for the control samples was $0.059 \pm 0.008 \mathrm{mgkg}^{-1}$ but after dipping in mild detergent followed by thorough washing under tap water there was a reduction in the levels to $0.018 \pm 0.006 \mathrm{mg} \mathrm{kg}^{-1}$.

The detergent used in this work was anionic detergent formulated for household dishwashing. This detergent is very soluble in water and therefore the treated lettuce can be wash under running water for $5 \mathrm{~min}$ to remove any traces of the detergent on the vegetable. And if there is any detergent residue, it may be too miniscule to cause any harm to the health of consumers (Swisher, 1987). This is because the acute toxicity of anionic surfactant which is used in the formulation of household dishwasher in animals is low after skin contact or oral intake (Madsen et al., 2001).

\section{Conclusion}

This study was carried out to determine the extent of removal of chlorpyrifos residues from lettuce through household treatment process such as washing with tap water, washing with salt solution and washing with $1 \%$ detergent solution. And also measure extent of chrloripyrifos accumulation during the cultivation of lettuce. Residue levels of chlorpyrifos were above the Maximum Residue Levels on vegetables that were analysed $1 \mathrm{~h}$ after pesticide application. These levels were reduced by $17.9 \%$ and $91.1 \%$ at $24 \mathrm{~h}$ and 7 days after application respectively. Despite the loss of some of the chlorpyrifos applied onto the lettuce $24 \mathrm{~h}$ after application, residues found on the foliage were high above the MRL in most of the samples. This could pose risk if lettuce is consumed as fresh vegetables and not properly wash. Therefore, it is important to allow at least 1-week (7 days) withholding period. After such a period, the residue concentrations were found to be below the MRL in samples where the pesticide was detected.

A comparison of the effects of different pre-household treatment procedures on the levels of chlorpyrifos in the lettuce samples, indicated that levels of chlorpyrifos residues were reduced significantly by washing with salt solution and $1 \%$ detergent solution. Tap water washing did not show any significant effect on the chlorpyrifos levels on the foliage of lettuce plant. Hence to reduce the risk associated with intake of chlorpyrifos through lettuce, mild detergent washing procedures should be followed before consumption. Nevertheless, lettuce should be rinsed thoroughly after the use of detergent, otherwise the detergent may be consumed together with the vegetables.

\section{Competing interests}

Authors declare that they have no competting interest.

\section{Authors' contribution}

Authors contributed equally. All authors have read and approved the final manuscript.

\section{Acknowledgement}

The work was supported by the Ghana Government Research Allowance and the MSc. Fellowship by the Scholarship secretariat in Ghana. The authors are to the staff of the Pesticide Residues Laboratory of Ghana Standards Authority for providing the laboratory assistance.

\section{Author details}

${ }^{1}$ Department of Chemistry, Kwame Nkrumah University of Science and Technology, Kumasi, Ghana. ${ }^{2}$ Department of Theoretical and Applied Biology, Kwame Nkrumah University of Science and Technology, Kumasi, Ghana. ${ }^{3}$ Department of Physics, Kwame Nkrumah university of Science and Technology, Kumasi, Ghana.

Received: 21 April 2016 Accepted: 18 August 2016

Published online: 30 August 2016

\section{References}

Akoto O, Andoh H, Dark G, Eshun K, Osei-Fosu P. Health risk assessment of pesticides residue in maize and cowpea from Ejura, Ghana. Chemosphere. 2013;92:67-73.

Akoto O, Gavor S, Appah MK, Apau J. Estimation of human health risk associated with the consumption of pesticide-contaminated vegetables from Kumasi, Ghana. Environ Monit Assess. 2015;187:244. doi:10.1007/s10661-015-4471-0.

Amoah P, Dreschel P, Abaidoo RC, Ntow WJ. Pesticide and pathogen contamination of vegetables in Ghana's urban markets. Arch Environ Contam Toxicol. 2006;50(1):1-6.

Bhanti M, Taneja A. Contamination of vegetables of different seasons with organophosphorus pesticides and related health risk assessment in Northern India. Chemosphere. 2007;69:63-8.

Clarke EEK, Levy LS, Spurgeon A, Calvert IA. The Problems Associated with Pesticide Use by Irrigation Workers in Ghana. Occup Med. 1997:47(5):301-8.

Dhiman N, Jyot G, Bakhshi AK. J Food Sci Technol. 2006;43(1):92-5.

Essumang DK, Dodoo DK, Adokoh CK, Fumador EA. Analysis of some pesticide residues in tomatoes in Ghana. Hum Ecol Risk Assess. 2008;14(4):796-806.

FAO/WHO. Food Standards Programme. Codex Alimentarius Commission, Twenty-seventh Session, Geneva, Switzerland. 28 June - 03 July, 2004. 2004.

Gerken A, Suglo JV, Braun M (2013) Crop Protection Policy in Ghana. Pokuase Accra: Integrated Crop Protection Project, PPRSD/GTZ;

Hui TJ, Ariffin MM, Tahir NM. Hydrolysis of chlorpyrifos in aqueous solutions at different temperatures and pH. Malaysian J Anal Sci. 2010;14(2):50-5.

Kim SW, Abd El-Aty AM, Rahman M, Choi JH, Lee YJ, Ko AY, Choi OJ, Shim JH. The effect of household processing on the decline pattern of dimethomorph in pepper fruits and leaves. Food Control. 2015;50:118-24. 
Kotey AD, Gbewonyo WSK, Afreh-Nuamah K. High chlorpyrifos levels on vegetables in Ghana. Pesticide News. 2008;80:1-6.

Krol WJ, Arsenault TL, Pylypiw HM, Mattina MJI. Connecticut Agricultural Experiment Station. J Agric Food Chem. 2000;48(10):4666.

Kumari B. Effects of household processing on reduction of pesticide residues in vegetables. ARPN J Agric Biol Sci. 2008;3(4):46-51.

Ling Y, Wang H, Yong W, Zhang F, Sun L, Yang ML, Wu YN, Chu XG. The effects of washing and cooking on chlorpyrifos and its toxic metabolites in vegetables. Food Control. 2011;22:54-8. doi.org/10.1016/j.

Lopez-Fernandez R, Rial-Otero O, Simal-Gandara J. Factors governingthe removal of mancozeb residues from lettuces with washing solutions. Food Control. 2013;34:530-8.

Madsen T, Boyd HB, Nylén D, Pedersen AR, Petersen Gl, Simonsen F. Environmental and Health Assessment of Substances in Household Detergents and Cosmetic Detergent Products. 2001. Environmental Project No. 6152001 Miljøprojekt.

Obeng-Ofori D, Owusu EO, Kaiwa ET. Variation in the level of carboxylesterase activity as an indicator of insecticide resistance in populations of the 102 diamondback moth Plutella xylostella (L.) attacking cabbage in Ghana. J Ghana Sci Assoc. 2002;4(2):52-62

Reigart JR, Roberts JR. Organophosphate Insecticides. Recognition and management of Pesticide Poisonings. 5th ed. 1999. p. 34-48.

Roberts TR, Hutson DH. Metabolic Pathways of Agrochemicals - Part 2: Insecticides and Fungicides. Cambridge: The Royal Society of Chemistry; 1999. p. 235-42.

Slavin JL, Lloyd B. Health Benefits of Fruits and Vegetables. Adv Nutr Int J. 2012:3:506-16.

Smith GN. Ultraviolet light decomposition studies with Dursban and 3,5,6trichloro-2-pyridinol. J Econ Entomol. 1968;61(3):793-9.

Swisher RD (1987). Surfactant Biodegredation (Second.). New York, New York: Marcel Dekker Inc. Retrieved from http://books.google.com/books. Accessed 10 June 2016.

Thompson CM, Richardson RJ. Anticholinesterase Insecticides. In: Marrs TC, Ballantyne B, editors. Pesticide Toxicology and International Regulation. West Sussex: Wiley; 2004. p. 89-127.

\section{Submit your manuscript to a SpringerOpen ${ }^{\circ}$ journal and benefit from:}

- Convenient online submission

- Rigorous peer review

- Immediate publication on acceptance

- Open access: articles freely available online

- High visibility within the field

- Retaining the copyright to your article 